\title{
Estimation of Curvature Changes for Steel-Concrete Composite Bridge Using Fiber Bragg Grating Sensors
}

\author{
Donghoon Kang ${ }^{1}$ and Wonseok Chung ${ }^{2}$ \\ ${ }^{1}$ Advanced Infrastructure Research Team, Korea Railroad Research Institute, 360-1 Woram-dong, \\ Gyeonggi-do, Uiwang-si 437-757, Republic of Korea \\ ${ }^{2}$ Department of Civil Engineering, Kyung Hee University, Gyeonggi-do, Yongin-si 446-701, Republic of Korea
}

Correspondence should be addressed to Wonseok Chung; wschung@khu.ac.kr

Received 5 September 2013; Revised 1 November 2013; Accepted 1 November 2013

Academic Editor: Noriah Bidin

\begin{abstract}
Copyright (C) 2013 D. Kang and W. Chung. This is an open access article distributed under the Creative Commons Attribution License, which permits unrestricted use, distribution, and reproduction in any medium, provided the original work is properly cited.

This study is focused on the verification of the key idea of a newly developed steel-concrete composite bridge. The key idea of the proposed bridge is to reduce the design moment by applying vertical prestressing force to steel girders, so that a moment distribution of a continuous span bridge is formed in a simple span bridge. For the verification of the key technology, curvature changes of the bridge should be monitored sequentially at every construction stage. A pair of multiplexed FBG sensor arrays is proposed in order to measure curvature changes in this study. They are embedded in a full-scale test bridge and measured local strains, which are finally converted to curvatures. From the result of curvature changes, it is successfully ensured that the key idea of the proposed bridge, expected theoretically, is viable.
\end{abstract}

\section{Introduction}

A steel-concrete composite Rahmen bridge is one that the piers and girders are constructed as a monolithic structure. This type of bridge is widely constructed due to merits such as cost effectiveness in construction and maintenance, resistance in earthquake, and high quality in driving. A new structural system of steel-concrete composite Rahmen bridge is currently developed to increase the span length. The key technology of the new bridge is introducing a prestressing force to steel girders by applying vertical prestress to steel bars already embedded at the pier wall. By means of this technique, a moment distribution of a continuous span bridge is formed in a simple span bridge. This eventually reduces both the design moment of the bridge and the size of the bridge section. In order to verify the viability of the proposed key technology, it is necessary to evaluate the structural behavior of the bridge among construction stages.

In general, concrete material should be cured at least 28 days to achieve the strength. The fabrication of a test bridge requires four major construction stages. Thus, in order to evaluate the expected behavior of the test bridge, curvature changes at four discrete construction stages are need to be monitored. However, since the proposed bridge system has sequential construction stages, long-term monitoring capability including absolute measurement and temperature compensation is important requirement of the sensing system for the test. Considering requirements necessary to the sensing system, fiber Bragg grating (FBG) sensors can be a good candidate because they can be easily applied to structures as multiplexed sensor arrays by embedment.

FBG sensors have already been applied to many structures in various fields by both embedment [1-4] and surface attachment [5] in many countries, and now they became popular sensors for detecting physical properties such as strain $[1,2,4,6]$ and temperature $[7,8]$ of structural behavior. Further applications are studied to detect corrosion in concrete $[3,9]$ and geomaterial [10].

Even though many applications are reported, not many FBG applications have been done in long-term monitoring of large civil structures such as bridge using embedded FBG sensors. The embedment is an important requirement for the data acquisition of large civil structure under severe environmental states such as concrete pouring. In the structural 
monitoring of civil structures, the interrogator needs to be sometimes unplugged due to site condition. Thus, the absolute measurement capability is required to effectively measure the physical quantities in the structures. Electric strain gauges have limitations that need initializing process like balancing. Under these circumstances, this study carefully selects FBG sensors as the most suitable sensing system because FBG sensors guarantee absolute measurement.

To conclude, this paper investigates the viability of the proposed key idea of a new bridge structure. For this purpose, a full-scale test bridge is designed and sequentially constructed in the laboratory. During the construction, two arrays of FBG sensors are embedded into the bridge to measure local strains. After that, the curvature changes converted from local strains of FBG sensors are compared sequentially at each construction stage.

In detail, FBG sensor arrays are composed of 4 pairs of local point sensors and are attached to steel girders at various longitudinal locations of the test bridge. From strains of eight discrete points, curvature, of the bridge is calculated based on plane section assumption and the curvature change at each construction stage is compared one another to verify the key feature of the proposed bridge.

In this paper, the key feature of the new bridge is briefly introduced first. A measurement scheme for the bridge is then presented. Subsequently, a full-scale bridge test is carried out to ensure the key idea of the proposed bridge. Finally, the experimental observation of the test bridge is presented.

\section{Key Feature of the New Bridge}

The key feature of the new steel-concrete composite bridge is vertical prestressing. Prestressing effect is introduced to steel girders already embedded at the pier wall in vertical direction. Thus, a moment distribution of a simple span bridge becomes the same with that of a continuous bridge. This idea is able to decrease the design moment of the bridge and consequently to reduce the size of bridge section.

The new bridge has additional supports composed of high-strength bars for prestressing at the pier wall in addition to ordinary steel supports. In other words, the proposed bridge has a structural system of continuous span that has a distance ( $e$ ) between two supports on the bridge ends, as shown in Figure 1. When steel bars are prestressed with a hydraulic system, upward camber occurs on the steel girders due to leverage, and pure bending moments also occur on the steel girders at the same time, as shown in Figure 1(a). After that, when reinforced concrete is placed at edges and in the slab followed by concrete pouring, the moment generated by the weight is combined with the moment generated previously by eccentricity, with the result that the positive moment at the midspan and the negative moment at the support are evenly distributed, as shown in Figure 1(b).

While general steel-concrete composite bridges exhibit the moment distributions of a simple span, the bending moments on the proposed bridge are positive at the girder center and negative at the support. This means that the bending moment created when placing slab concrete is

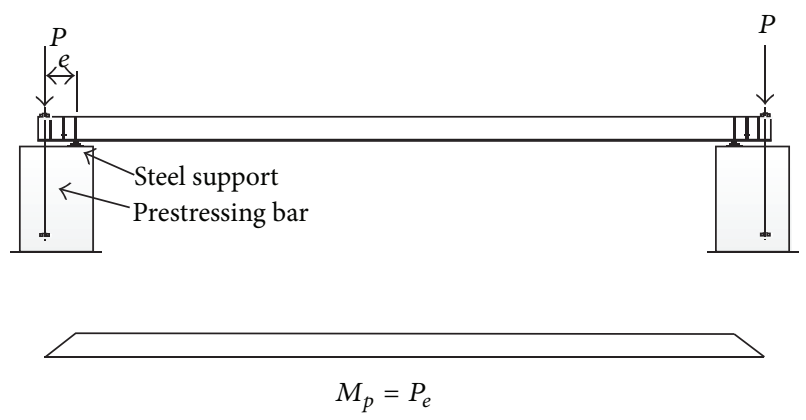

(a) After prestressing

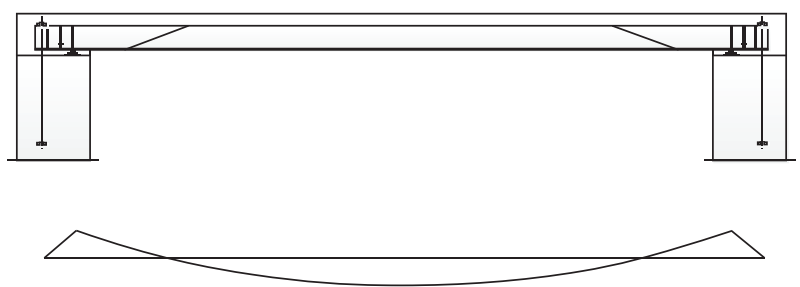

(b) After deck concrete placement

FIGURE 1: Principle of vertically prestressed composite bridge.

distributed both at the girder center and at the support; as a result, the positive moment generated at the center decreases as much as the negative moment at the support. In other words, economic benefits can be anticipated from an efficient stress distribution.

The advantage of the proposed bridge is that it reduces the amount of steel materials used by distributing bending moments generated at the midspan and supports of the bridge when composite slab concrete is placed prior to composition. In this study, based on the aforementioned principle, it is now important to experimentally evaluate the actual curvature distribution of the proposed bridge under each construction stages since the moment distribution is directly related to the curvature distribution.

\section{Test Program}

3.1. Construction of Test Bridge. In this study, a $14.2 \mathrm{~m}$ long and $2.4 \mathrm{~m}$ wide full-scale test bridge was fabricated compositely with reinforced concrete deck. The layout of the test bridge is shown in Figure 2 in detail. This bridge was constructed through three stages. In the first stage, pier walls were constructed and were completely fixed on the strong floor in the structural laboratory. After that, the readily placed high-strength rebars with the diameter of $32 \mathrm{~mm}$ were installed inside the pier walls in the vertical direction. Two steel girders were then placed on the abutments. In the second stage, the girder was prestressed in vertical direction as presented earlier. Lastly, after the end of prestressing, concrete for the bridge deck and the corner of the rigid frame bridge was casted and cured compositely. The construction of the test bridge took 38 days. Photograph of the completed test bridge is shown in Figure 3. 


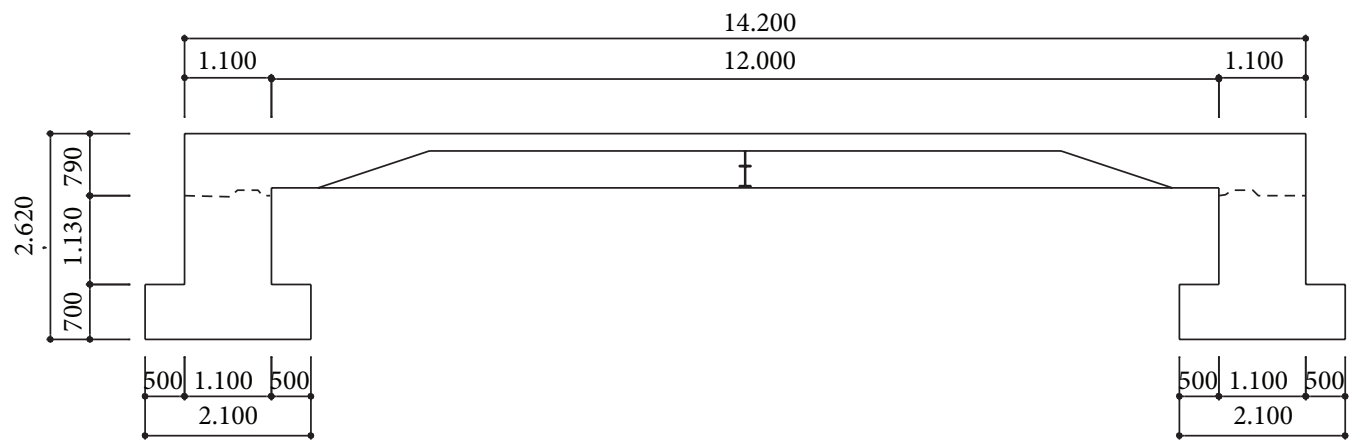

(a) Front view

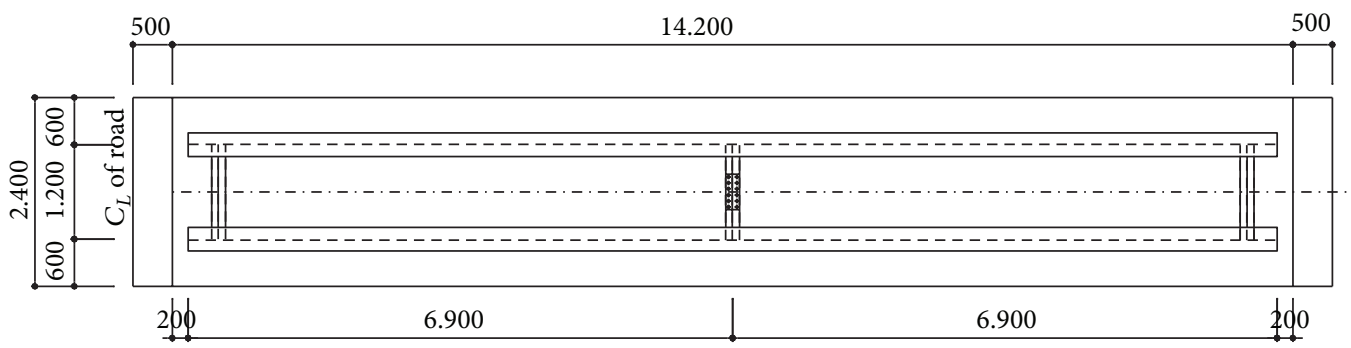

(b) Top view

FIgURE 2: Layout of a test bridge.

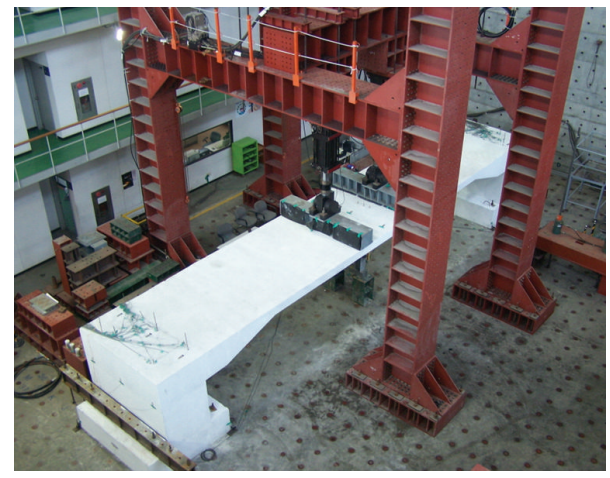

FIGURE 3: Photograph of test bridge.

3.2. FBG Sensing Principles. In order to detect the changes of curvature distribution at each construction stage, two channels of FBG sensors were installed in both top and bottom portion of the girder by surface attachment and then embedded into concrete through the casting. During the third stage, the interrogator for embedded sensors should be unplugged due to the harsh condition of the installation site. Therefore, it is difficult to acquire exact strain values from sensors when the sensor system used needs initializing process like balancing in electric strain gauges. This limitation explains well enough why the FBG sensors were chosen as the most suitable sensors in this study because they guarantee absolute measurement. In other words, FBG sensors offer the absolute value for physical parameters such as strain and temperature whenever the interrogator was connected to the sensors because the signal processing is done by calculating the wavelength shift in FBG sensors, which is one of the unique characteristics of light.

FBG sensors for this study were produced using the phase mask method devised by Hill et al. [11]. When an ultraviolet ray is introduced to the phase mask, a particular interference pattern is formed inside the core of an optical fiber-this pattern is called a fiber Bragg grating. This grating reflects part of the incident light in a very narrowband, called the Bragg wavelength, $\lambda_{B}=2 n_{e} \Lambda$, where $n_{e}$ is the effective refractive index of the fiber core and $\Lambda$ is the grating period. A Bragg wavelength reflected under the Bragg condition is a function of the effective refractive index and grating interval. When external disturbances are applied to the grating part, the grating period is changed. Consequently, the Bragg wavelength also changes $\left(\Delta \lambda_{B}\right)$. The Bragg wavelength change is related to the strain $(\varepsilon)$ and the temperature change $(\Delta T)$ as

$$
\Delta \lambda_{B}=\lambda_{B}\left[\left(\alpha_{f}+\xi_{f}\right) \Delta T+\left(1-p_{e}\right) \varepsilon\right],
$$

where $\alpha_{f}$ is the coefficient of thermal expansion, $\xi_{f}$ is the thermooptic coefficient, and $p_{e}$ is the strain-optic coefficient of an optical fiber.

If FBG sensors are used to monitor long-term behavior of the bridge including construction stages where strain and temperature are coupled, temperature compensation should be appropriately evaluated. Assuming strain-free condition, the temperature can be simply calculated by measuring the wavelength shift in the reflected wavelength spectrum. Thermal effect can be removed by decoupling $\Delta T$ using (2):

$$
\Delta T=\frac{1}{\alpha_{f}+\xi_{f}} \frac{\Delta \lambda_{B}}{\lambda_{B}} .
$$




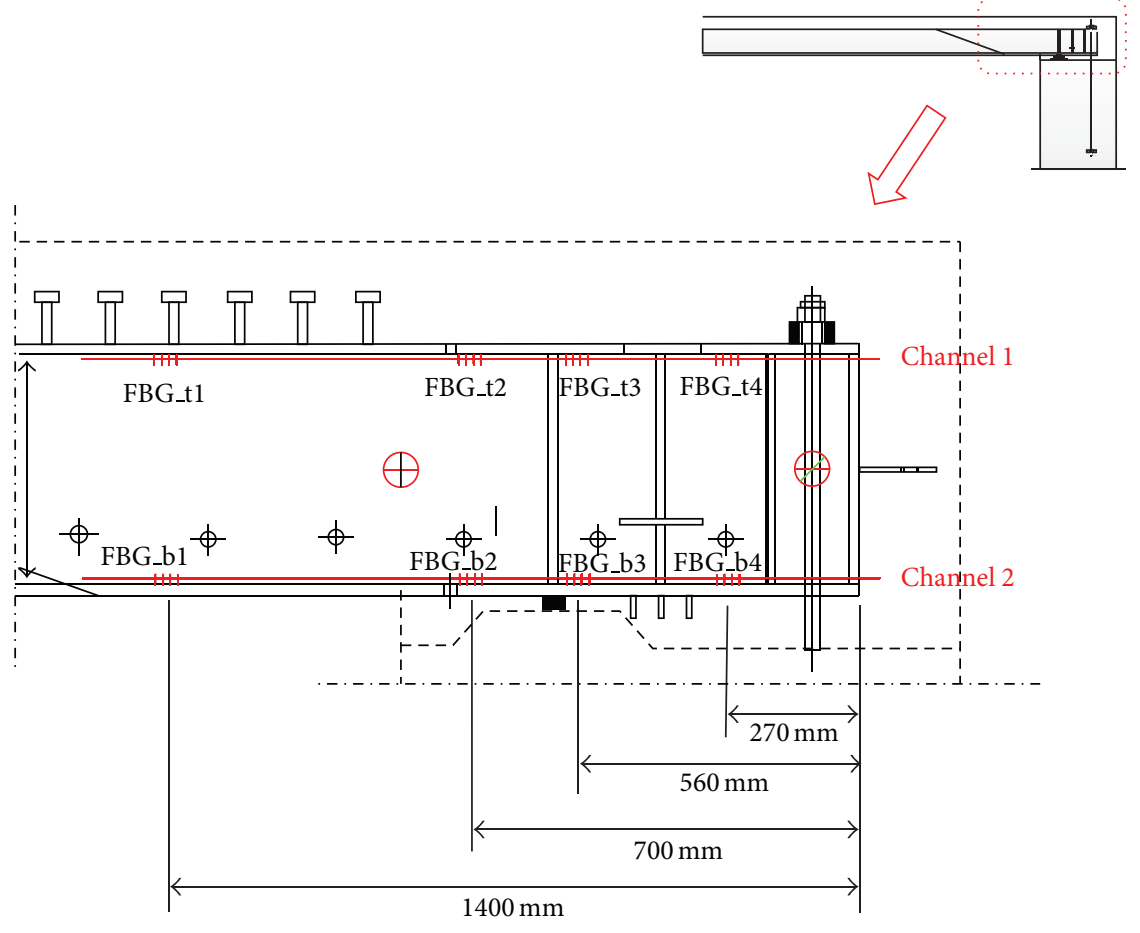

FIGURE 4: Layout of FBG sensor arrays at joint region.

In this study, the temperature was measured simultaneously throughout construction stages. When an FBG sensor is applied to a structure that is under only a thermal strain, the net wavelength change of the FBG sensor can be expressed as the sum of two terms; the first is a refractive index change and the second is the thermal strain of the structure itself. The pure thermal strain of the structure itself can be expressed as follows [12]:

$$
\varepsilon_{\mathrm{th}}=\frac{1}{1-p_{e}}\left[\frac{\Delta \lambda_{B}}{\lambda_{B}}-\xi_{f} \Delta T\right] .
$$

An interrogation system used in this study is IS-7000 FBG Interrogator, which is manufactured by FiberPro Co. [13] based on a wavelength-swept fiber laser (WSFL) [14], which has a scanning tunable filter to increase the output power of the laser source. The resolution of the sensing module is less than $1 \mathrm{pm}(0.83 \mu \varepsilon)$, and the wavelength measurement accuracy is typically less than $\pm 5 \mathrm{pm}(4.15 \mu \varepsilon)$.

3.3. Measurement Scheme. Multiplexing capability is the most practical advantage of the FBG sensor because it enables the use of several FBG sensors in a single optical fiber in series. In other words, multiplexed arrays of FBG sensors allow for the measurement of strains at discrete locations on a given structure.

In this study, four FBG sensors are multiplexed in a single optical fiber and installed in parallel pairs along the steel girder by surface attachment, with one set at the top portion (Channel 1) and the other at the bottom portion (Channel 2) of the test bridge, as shown in Figure 4. Significant moment changes are expected during construction stage at the joint between pier and superstructure. Thus, the longitudinal positions of FBG sensors are carefully selected to ensure the curvature distribution which is the key behavior of the test bridge. The vertical distance between two multiplexed FBG sensor lines is $452 \mathrm{~mm}$ which is the height of web. FBG sensors are directly attached to the surface of the structure using epoxy glue.

Multiplexed FBG sensors are installed to monitor curvature changes from measured strains under each construction stage. Only the joint part of the bridge is considered since the monitoring of this part provides key information on the proposed bridge. The test was performed in such a way that each girder was loaded symmetrically with small increments up to $500 \mathrm{kN}$ using two vertical hydraulic actuators, located $2 \mathrm{~m}$ apart and equidistant from the center of the girder, as shown in Figure 5.

\section{Test Results and Discussions}

The FBG sensors continuously monitor strain-induced wavelength shifts throughout the entire experiment. Figure 6 shows the spectrum of reflected FBG sensor signals induced by prestressing at both top (Channel 1) and bottom flange (Channel 2) of the girder. For instance, strain-induced wavelengths in Channel 1 are shifted to the negative direction since the structures are in a state of tension. From the shift of peak signals, the multiplexed FBG sensors located in the top are under tension, and the others are under compressive strain. This tendency agrees very well with the expectations aforementioned in the previous section, which exhibits the negative curvature at the support region. 


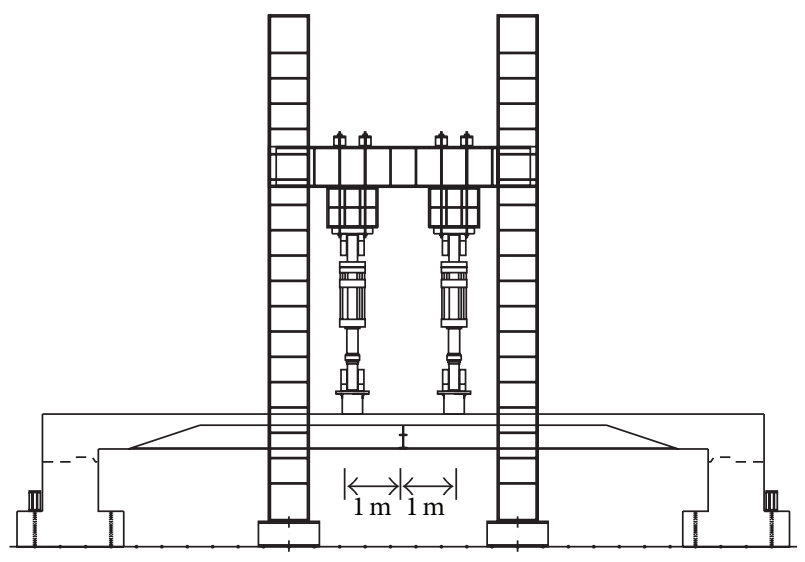

Figure 5: Test setup.

The local strain can be directly measured from the FBG sensors. Under the assumption that the plane cross-sections of a beam remain plane under pure bending and FBG sensors are installed parallel to the neutral axis at the same longitudinal location, the curvature $\left(\kappa_{i}\right)$ for an instrumented section is approximated by

$$
\kappa_{i}=\frac{\varepsilon_{i}^{\text {bot }}-\varepsilon_{i}^{\text {top }}}{h},
$$

where $\varepsilon_{i}^{\text {bot }}$ and $\varepsilon_{i}^{\text {top }}$ are the bottom strain and top strain of the $i$ th longitudinal location, respectively. $h$ is the vertical distance between FBG sensors at the same longitudinal location. The curvature will have the same sign as the moment for the section. The moment at ith longitudinal location can be determined by multiplying flexural rigidity $(E I)$ and corresponding curvatures as

$$
M_{i}=E_{i} I_{i} \kappa_{i},
$$

where subscript $i$ implies the longitudinal location of the test bridge. It is noted that moment distribution of the proposed bridge can be estimated from curvature distribution since flexural rigidity is almost constant in longitudinal direction.

Figure 7 shows curvature distribution of steel girders induced by prestressing in the joint region. It should be noted that test results had readily considered the temperature compensation. It is clear that curvature distribution just after prestressing or just before concrete pouring exhibits expected distribution shape of curvature, which is constant inside support and decreased to zero outside support, as theoretically expected in Figure 1(a). After vertical prestressing, reinforcement is placed in the formwork of deck concrete. This additional work just before pouring concrete for deck slab slightly changes curvature distribution in the joint region.

Figure 8 shows curvature distribution of steel girders induced by self-weight of deck concrete placement and load applications. After deck concrete placement, curvatures inside support are no longer constant but decreased toward midspan. The magnitude of curvature or moment also increases as the applied load increases. This tendency

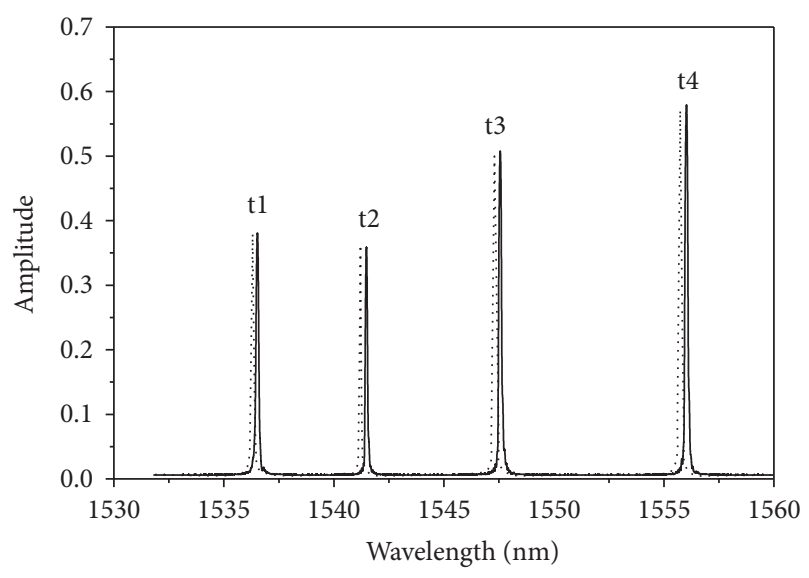

(a) Channel 1 (top)

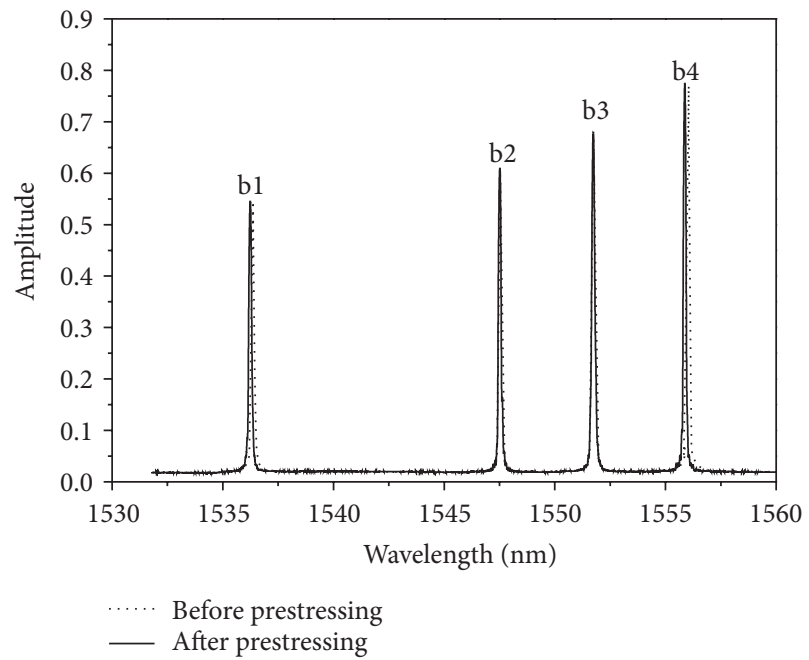

(b) Channel 2 (bottom)

FIGURE 6: Wavelength shift induced by prestressing.

illustrates the similarity with that of joint region in frame structures, as expected in Figure 1(b).

The curvature of the test bridge was theoretically predicted to decrease to zero which is a point of inflection, as illustrated in Figure 1(b). The direction of curvature changes at the point of inflection. In order to predict the point of inflection of the test bridge, preliminary finite element analyses were performed. The test bridge can be largely divided into the pier wall, steel girders, cross beams, slab, and vertical tendons. In order to consider three-dimensional behaviors of vertically prestressed composite rigid frame bridges, a numerical analysis model was established by using shell elements and three-dimensional fiber beam elements. The vertical prestressing bar was idealized by truss elements, and the prestressing forces are specified as an initial stress in each truss elements. A completed three-dimensional finite element model is shown in Figure 9. The commercial finite element program used for the numerical analysis was ABAQUS [15]. The compressive strength of concrete material model is $21 \mathrm{MPa}$. Table 1 shows parameters of steel material model. 

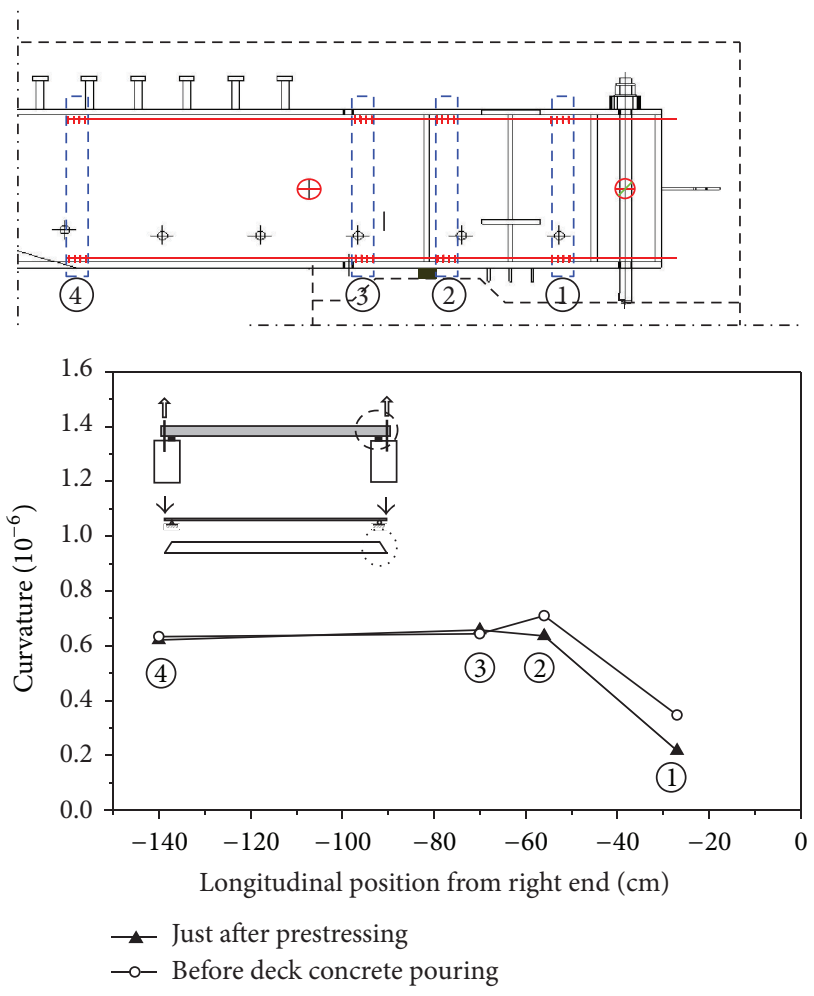

FIgURE 7: Curvature distribution after prestressing and before concrete pouring.
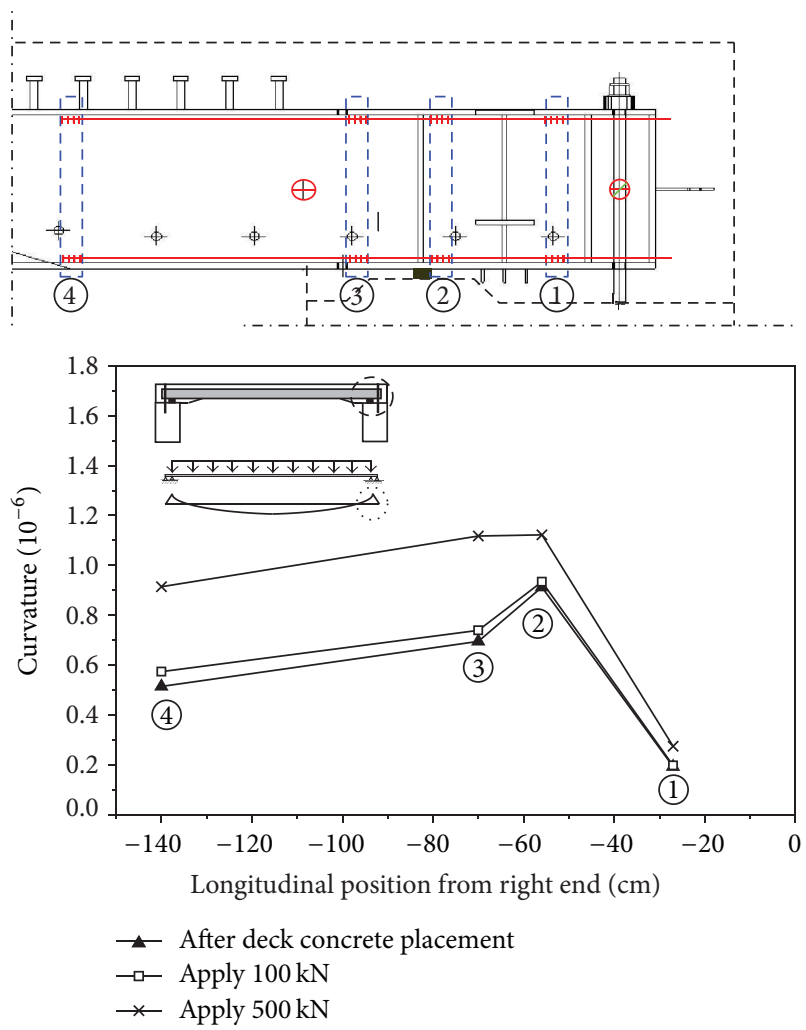

FIgURE 8: Curvature distribution after concrete placement and in service.

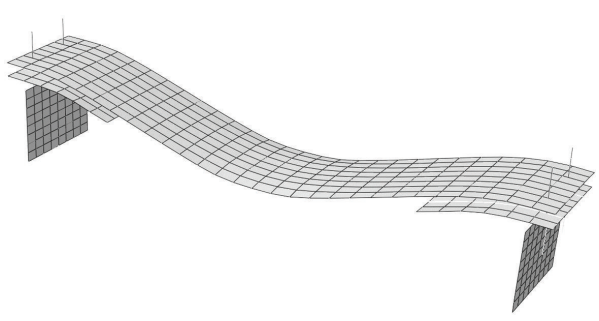

FIgURE 9: Finite element model of test bridge.

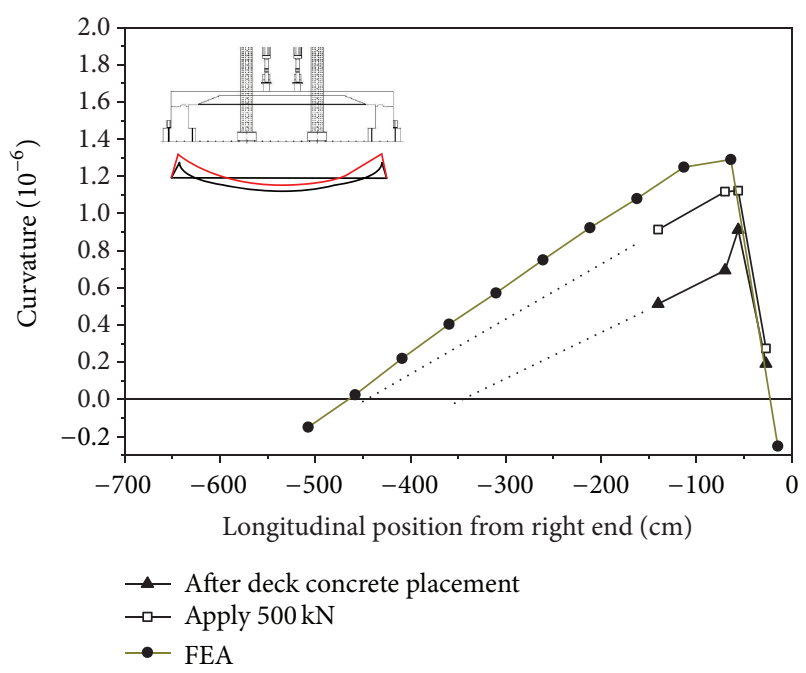

FIGURE 10: Prediction of curvature distribution.

TABLE 1: Material model.

\begin{tabular}{lcccc}
\hline & $\begin{array}{c}\text { Modulus of } \\
\text { elasticity } \\
(\mathrm{GPa})\end{array}$ & $\begin{array}{c}\text { Yield } \\
\text { stress } \\
(\mathrm{MPa})\end{array}$ & $\begin{array}{c}\text { Ultimate } \\
\text { stress } \\
(\mathrm{MPa})\end{array}$ & $\begin{array}{c}\text { Poisson's } \\
\text { ratio }\end{array}$ \\
\hline $\begin{array}{l}\text { Steel } \\
\text { (reinforcement) }\end{array}$ & 170 & 439 & 580 & 0.3 \\
$\begin{array}{l}\text { Steel (girder) } \\
\begin{array}{l}\text { Steel } \\
\text { (prestressing bar) }\end{array}\end{array}$ & 200 & 400 & 544 & 0.3 \\
\hline
\end{tabular}

A detailed description of the finite element formulation is outside of the scope of this paper.

Figure 10 presents the curvature distribution from the test and finite element analysis. From the measured curvature in the joint region, the linear lines are added as dashed lines, and the point at which curvature becomes zero (i.e., inflection point, IP) is estimated. The measured IP and predicted IP are estimated $450 \mathrm{~cm}$ and $465 \mathrm{~cm}$ when the applied load is $500 \mathrm{kN}$, respectively.

From all the experimental results, it was obviously proved that the proposed bridge can have a moment distribution of a continuous span bridge though it has a simple span. The verification scheme using multiplexed FBG sensor array was proven to be effective. In addition, FBG sensors were successfully embedded inside the bridge and well responded 
under harsh construction condition throughout various construction stages.

\section{Summary and Conclusions}

The main feature of the new steel-concrete composite bridge was verified using embedded FBG sensor arrays. The key was to ensure the curvature distribution change at every construction stage including prestressing, reinforcement placement, concrete pouring, and load application. In this study, a fullscale test bridge was designed, constructed, and tested in the structural laboratory. For considering site conditions, multiplexed FBG sensors that guarantee absolute measurement were embedded in the test bridge to verify theoretically expected behavior in the joint part of the bridge.

Measurement scheme based on a pair of multiplexed FBG sensor arrays was successfully implemented. Local strains of top and bottom flange were effectively obtained using multiplexed FBG sensors during the whole construction stages. The curvatures are then calculated based on the plane section assumption from measured strains. The curvature distribution of the test bridge at each construction stage was proven to be valid with being compared to theoretically expected behavior and finite element analysis results.

The measurement scheme based on embedded FBG sensor arrays provides an effective tool for capturing the behavior of the proposed bridge structure. It is ensured that the proposed FBG sensor-based monitoring scheme is able to capture long-term behavior of bridge building process under harsh construction condition by taking advantage of absolute measurement characteristics of FBG sensor.

\section{Acknowledgment}

This work was supported by a Grant from Ministry of Land, Infrastructure and Transport. (Project no.: 13CCTI-C06150903).

\section{References}

[1] D. H. Kang, C. U. Kim, and C. G. Kim, "The embedment of fiber Bragg grating sensors into filament wound pressure tanks considering multiplexing," NDT and E International, vol. 39, no. 2, pp. 109-116, 2006.

[2] W. Chung and D. Kang, "Full-scale test of a concrete box girder using FBG sensing system," Engineering Structures, vol. 30, no. 3, pp. 643-652, 2008.

[3] W. Chen and X. Dong, "Modification of the wavelength-strain coefficient of FBG for the prediction of steel bar corrosion embedded in concrete," Optical Fiber Technology, vol. 18, no. 1, pp. 47-50, 2012.

[4] P. Biswas, S. Bandyopadhyay, K. Kesavan et al., "Investigation on packages of fiber Bragg grating for use as embeddable strain sensor in concrete structure," Sensors and Actuators A, vol. 157, no. 1, pp. 77-83, 2010.

[5] D. Kang and W. Chung, "Integrated monitoring scheme for a maglev guideway using multiplexed FBG sensor arrays," NDT and E International, vol. 42, no. 4, pp. 260-266, 2009.
[6] K. Lau, L. Yuan, L. Zhou, J. Wu, and C. Woo, "Strain monitoring in FRP laminates and concrete beams using FBG sensors," Composite Structures, vol. 51, no. 1, pp. 9-20, 2001.

[7] S. Kang, D. Kang, and C. Kim, "Real-time monitoring of transverse thermal strain of carbon fiber reinforced composites under long-term space environment using fiber optic sensors," NDT and E International, vol. 42, no. 5, pp. 361-368, 2009.

[8] S. Daud, M. A. Jalil, S. Najmee, S. Saktioto, J. Ali, and P. P. Yupapin, "Development of FBG sensing system for outdoor temperature environment," Procedia Engineering, vol. 8, pp. 386-392, 2011.

[9] J. Gao, J. Wu, J. Li, and X. Zhao, "Monitoring of corrosion in reinforced concrete structure using Bragg grating sensing," NDT and E International, vol. 44, no. 2, pp. 202-205, 2011.

[10] D. Xu, J. Yin, Z. Cao, Y. Wang, H. Zhu, and H. Pei, "A new flexible FBG sensing beam for measuring dynamic lateral displacements of soil in a shaking table test," Measurement, vol. 46, no. 1, pp. 200-209, 2013.

[11] K. O. Hill, B. Malo, and F. Bilodeau, "Bragg gratings fabricated in monomode photosensitive optical fiber by UV exposure through a phase mask," Applied Physics Letters, vol. 62, no. 10, pp. 1035-1037, 1993.

[12] J. S. Sirkis, "Unified approach to phase-strain-temperature models for smart structure Interferometric optical fiber sensor, part I: development," Optical Engineering, vol. 32, no. 4, pp. 752761, 1993.

[13] FiberPro Co, IS7000 User's Manual, FiberPro Co, Daejeon, Republic of Korea, 2006.

[14] S. H. Yun, D. J. Richardson, and B. Y. Kim, "Interrogation of fiber grating sensor arrays with a wavelength-swept fiber laser," Optics Letters, vol. 23, no. 11, pp. 843-845, 1998.

[15] ABAQUS, Inc, ABAQUS/Standard User's Manual: Version 6. 71, ABAQUS, Inc, Pawtucket, RI, USA, 2007. 

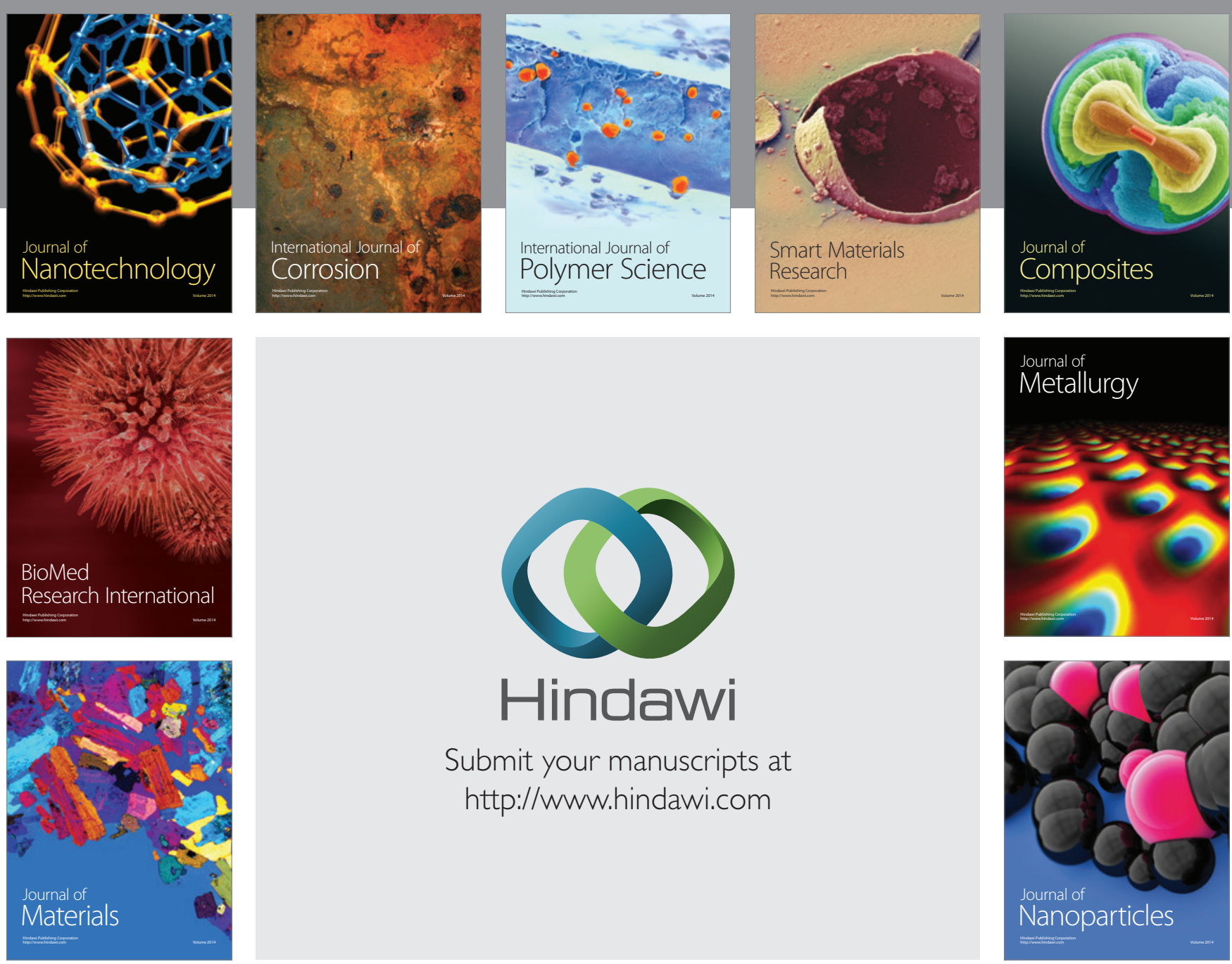

Submit your manuscripts at http://www.hindawi.com
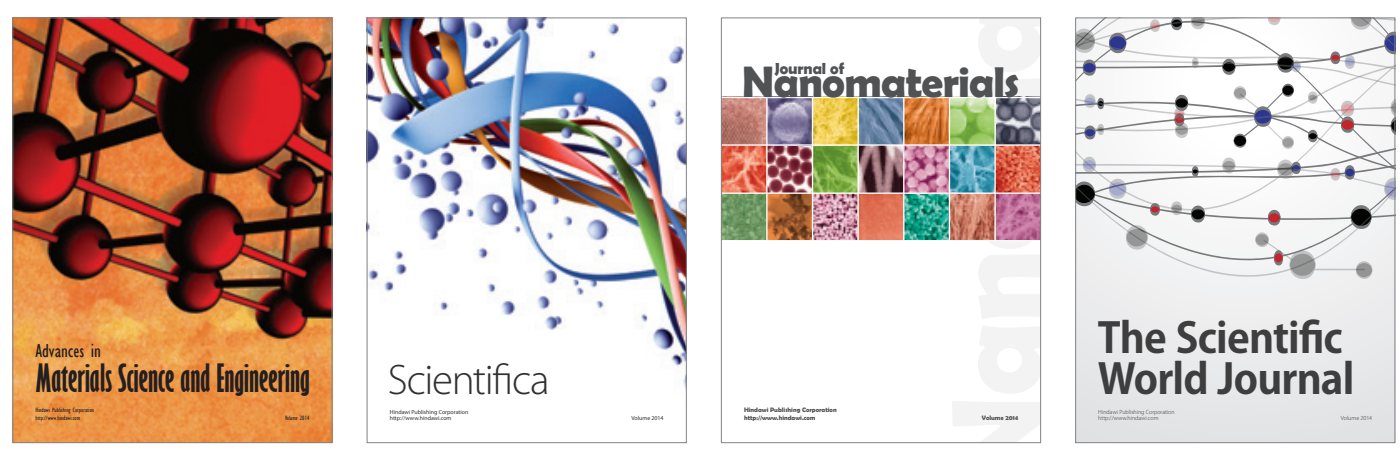

\section{The Scientific World Journal}
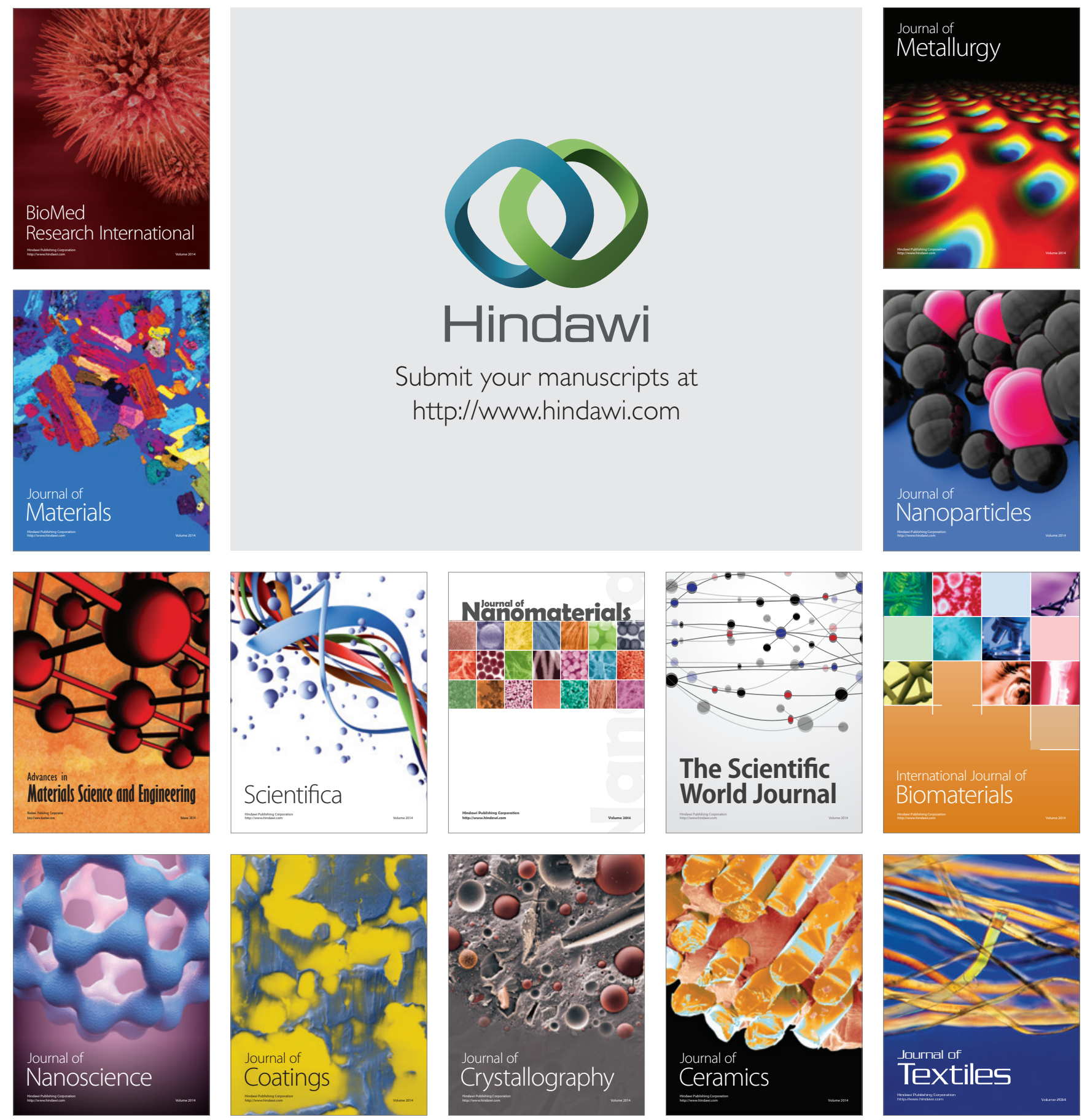